\title{
The rising tide of dementia deaths: triangulation of data from three routine data sources using the Clinical Practice Research Datalink
}

\author{
Shaleen Ahmad, lain M Carey*, Tess Harris, Derek G Cook, Stephen DeWilde and David P Strachan
}

\begin{abstract}
Background: Dementia is currently the leading certified underlying cause of death in England. We assess how dementia recording on Office for National Statistics death certificates (ONS) corresponded to recording in general practice records (GP) and Hospital Episode Statistics (HES).

Methods: Retrospective study of deaths (2001-15) in 153 English General Practices contributing to the Clinical Practice Research Datalink, with linked ONS and HES records.

Results: Of 207,068 total deaths from any cause, 19,627 mentioned dementia on the death certificate with 10,253 as underlying cause; steady increases occurred from 2001 to 2015 (any mention 5.3 to 15.4\%, underlying cause 2.7 to $10 \%$ ). Including all data sources, recording of any dementia increased from 13.2 to $28.6 \%$. In 2015 , only $53.8 \%$ of people dying with dementia had dementia recorded on their death certificates. Among deaths mentioning dementia on the death certificate, the recording of a prior diagnosis of dementia in GP and HES rose markedly over the same period. In 2001, only $76.3 \%$ had a prior diagnosis in GP and/or HES records; by 2015 this had risen to $95.7 \%$. However, over the same period the percentage of all deaths with dementia recorded in GP or HES but not mentioned on the death certificate rose from 7.9 to $13.3 \%$.

Conclusions: Dementia recording in all data sources increased between 2001 and 2015. By 2015 the vast majority of deaths mentioning dementia had supporting evidence in primary and/or secondary care. However, death certificates were still providing an inadequate picture of the number of people dying with dementia.
\end{abstract}

Keywords: Dementia, Mortality, Death certificates, Cause of death, Primary care

\section{Background}

Dementia is defined as the progressive, irreversible loss of cognitive functioning, usually occurring after age 65 years and encompassing many different subtypes, of which Alzheimer's is the commonest [1]. Although no gold standard exists for dementia ascertainment [2] an estimated 850,000 people in the UK are living with

\footnotetext{
* Correspondence: sgjd450@sgul.ac.uk
}

Population Health Research Institute, St George's University of London, Cranmer Terrace, SW17 ORE London, United Kingdom dementia [1], a significant burden for health and social care systems.

Dementia is now the most commonly certified underlying cause of death in England according to Office for National Statistics (ONS) figures, accounting for $12.7 \%$ of all registered deaths in 2017 [3]. It has overtaken cardiovascular causes as the leading underlying cause of death in the UK. ONS data suggests that death rates from dementia are steadily increasing in all older age groups ( $>65$ years) and in both males and females, but

(C) The Author(s). 2021 Open Access This article is licensed under a Creative Commons Attribution 4.0 International License, which permits use, sharing, adaptation, distribution and reproduction in any medium or format, as long as you give appropriate credit to the original author(s) and the source, provide a link to the Creative Commons licence, and indicate if changes were made. The images or other third party material in this article are included in the article's Creative Commons licence, unless indicated otherwise in a credit line to the material. If material is not included in the article's Creative Commons licence and your intended use is not permitted by statutory regulation or exceeds the permitted use, you will need to obtain permission directly from the copyright holder. To view a copy of this licence, visit http://creativecommons.org/licenses/by/4.0/ The Creative Commons Public Domain Dedication waiver (http://creativecommons.org/publicdomain/zero/1.0/) applies to the data made available in this article, unless otherwise stated in a credit line to the data. 
studies suggest that the age-specific incidence rates of dementia have fallen over the last two decades, driven primarily by a reduction of dementia diagnoses in men [4].

There has been increased public awareness of dementia due to Government initiatives such as the National Dementia Strategy [5] and the Prime Minister's Challenge on Dementia 2020 [6]. This was associated with incentivising primary care to record dementia diagnosis in the Quality and Outcomes Framework (QOF) [7], and dementia-related Read code changes introduced after 2006 [8]. There were high national general practice participation rates in the dementia care incentive schemes of Directed Enhanced Services 18 (DES18) and Dementia Identification Scheme (DIS) of 98.5 and $76 \%$ respectively [9]. In 2012 the Department of Health also introduced incentives to increase dementia diagnosis in secondary care, by case finding in older inpatients [8].

The aim of this work is to assess how well dementia recording in death certification relates to both routine recording in electronic general practice records and Hospital Episode Statistics (HES) over the period 2001 to 2015. The study period was chosen as it coincided with the introduction of the latest version of the International Classification of Diseases 10th revision (ICD10) [10], so codes relating to dementia were consistent over time and in addition to showing increases in dementia death rates, it also included key policy changes to QOF [8] and hospital recording [11].

\section{Methods}

This study used data from the Clinical Practice Research Datalink (CPRD GOLD), a national validated database of patient records collected during routine general practice consultations. Diagnoses are recorded on the system using a hierarchical clinical classification system called Read codes [12], either by staff at the time or from other sources such as discharge data from hospitals. As of 2015, CPRD had about 700 practices nationally which had contributed data ( $7 \%$ of the UK population), and the registered patients have been shown to be broadly representative of the UK population terms of age, sex and ethnicity [13]. The pseudo-anonymised information from this primary care database is linked to external data (HES and ONS) via an independent trusted third-party [14]. HES is a data source recording every NHS hospital admission in England containing information on clinical diagnoses [15]. ONS data include details from the death certificate for both the underlying cause of death and all causes mentioned on the death certificate. ONS death certificate data were linked to GP records via a unique patient identification number using a linkage algorithm while HES data were linked in a series of deterministic linkage steps [14].

\section{Study Sample}

In order that findings reflect trends over time, rather than differences due to practices entering and exiting CPRD over time, we restricted our study to 153 English practices that contributed up-to-standard data over the entire study period 2001 to 2015 . One of the criteria for this quality control measure carried out by CPRD is number of recorded deaths within a practice [16]. Additionally, the study was restricted to English practices as patients residing outside England are not linked to ONS mortality data or HES within CPRD [13].

All deaths over the period 2001-2015 were identified from the electronic General Practice (GP) records and then linked to ONS mortality to confirm the death. There is near agreement between the two sources, with $98.2 \%$ of deaths in ONS reported to be also identified in CPRD [17]. However, it is common for the CPRD date associated with the death to be on average 1 month later [18], so we used the ONS date for the date of death in our analyses. Codes for dementia of any type were identified within each of the GP, HES and ONS datasets. A patient was defined as having "died with dementia" if they had any evidence of a diagnosis of dementia on any of the three data sources.

\section{Dementia recording on GP electronic records}

Within the patient's primary care record we searched for diagnoses of dementia ("GP diagnosis") using specific Read codes indicating a diagnosis for dementia based on a standard code list in the QOF [7] (Supplementary Table 1). Additionally, we defined two further groups based on codes associated with dementia: "GP awareness", which is related to suspected memory impairment or other codes indicative of dementia without a formal diagnosis of dementia (Supplementary Table 2); "GP administration", which refers to other administrative codes on the GP system relating to dementia (Supplementary Table 3). "Any GP record" of dementia was based on the "GP diagnosis" category only, while the other categories were used to investigate recording patterns in patients identified as having dementia from their death certificate. To check whether length of registration prior to death had influenced recording, we carried out sensitivity analyses restricted to patients registered in their practice for at least a year before death.

\section{Dementia recording on HES and ONS}

Within the linked hospitalisations and mortality datasets we searched all records for evidence of a diagnosis of dementia, which are both coded using International Classification of Diseases version 10 (ICD-10) codes (Supplementary Table 4). For hospitalisations, HES Admitted Patient Care (HES APC) data are collected on all admissions to National Health Service (NHS) hospitals 
in England [15], with the primary reason for admission coded along with other major co-morbidities. Any recording of dementia was counted as evidence of a dementia diagnosis. For mortality, the ONS dataset extracts summary information from the Medical Certificate of the Cause of Death (MCCD), the document completed by a doctor involved in the care of the patient. It has two parts: conditions leading to death are recorded in Part 1 and other significant conditions contributing to the death are recorded in Part 2 [19]. Any recording was counted as evidence of a dementia diagnosis, but we sometimes make the distinction between "listed as underlying cause" (Part 1 only) and "any mention" (Part 1 or 2 ).

\section{Statistical Analyses}

Prevalence estimates of dementia recording are reported in the text with $95 \%$ confidence intervals calculated from the proportion recorded. A visual summary of the overlap recorded in the three data sources (GP, HES records and ONS mortality statistics) was represented by Venn diagrams in 2001 and 2015, using approximate scaling for each to represent the percentage of deaths recorded in the three data sources. A fixed-sized rectangle borders the diagram and represents $100 \%$ of deaths in each year. The plots were carried out using the Venn Diagram Plotter freely available from the Pacific Northwest National Laboratory [20].

\section{Results}

\section{Trends among all deaths}

Table 1 and Supplementary Fig. 1 summarise the trends in annual dementia recording in death certification, GP records and HES data in all deaths in the study population between 2001 and 2015. There were a total of 207,068 deaths in the study population, of which 19,627 (9.5\%) deaths had any mention of dementia (either as a contributory or underlying cause of death) on the death certificate. Dementia was listed as the underlying cause in 10,253 $(5.0 \%)$ deaths. There was an increasing trend in dementia recording in records from all three data sources: death certification, electronic GP health records and HES data.

In the ONS data any mention of dementia on the death certificate over the study period tripled, from $5.3 \%(95 \%$ CI $4.9-5.7 \%)$ to $15.4 \%$ (95\%CI 14.7 - $16.0 \%)$ whilst recording of dementia as the underlying cause of death increased from $2.7 \%$ (95\%CI $2.5-3.0 \%)$ to $10.0 \%$ (95\%CI $9.4-10.6 \%)$. Of deaths recorded as dementia on the death certificate, the proportion recording it as the underlying cause increased over this period from $51.3 \%$ (95\%CI $50.5-52.1 \%)$ to $65.0 \%$ (95\%CI 64.2 - 65.9\%). GP recording of dementia on electronic GP health records increased from $7.8 \%(95 \% \mathrm{CI} 7.4-8.3 \%)$ of all deaths in 2001 to $21.2 \%$ (95\%CI $20.5-21.9 \%$ ) in 2015.
HES records showed a similar pattern of increase in coding of dementia over the study period, with $7.8 \%$ (95\%CI $7.4-8.3 \%)$ of records including a dementia code in 2001 increasing to $23.8 \%(95 \%$ CI 23.0 - $24.5 \%)$ in 2015. When we limited analyses to patients registered in their practice for at least a year, findings were similar (Supplementary Table 5).

The triangulation of dementia recording from all 3 sources is shown in Fig. 1 for 2001 and 2015. There was an increase in dementia recorded in any one of the data sources, from $13.2 \%$ (95\%CI $12.7-13.8 \%$ ) of all deaths with dementia recorded in 2001 to $28.6 \%$ (95\%CI 27.8 $29.4 \%$ ) of all deaths in 2015. In particular there was a substantial increase in subjects with a dementia diagnosis from all 3 sources (grey area) rising from $1.5 \%$ $(95 \%$ CI $1.3-1.7 \%)$ in 2001 to $10.4 \%$ (95\%CI 9.8 $10.9 \%)$ in 2015.

However, relying on the death certificate alone for a diagnosis of dementia gives an incomplete picture of the number of people in England dying with dementia (i.e. all patients who die with a diagnosis of dementia from any source). While the percentage of all deaths with a diagnosis recorded in any of GP, HES or ONS captured by death certificates has risen from $40.2 \%$ to 2001 $(5.3 \% / 13.2 \%)$, it is still only approximately half $(53.8 \%$ $=15.4 \% / 28.6 \%$ ) of these deaths in 2015 (Fig. 1). Due to the increase in GP and HES recording, this means the percentage of all deaths with a dementia diagnosis recorded in GP or HES but not mentioned on the death certificate, has risen from 7.9 to $13.3 \%$.

\section{Trends among deaths with any mention of dementia on the death certificate}

Figure 2 illustrates trends in dementia related recording in GP or HES records amongst patients with any mention of dementia on the death certificate (Supplementary Table 6 provides the underlying data). The proportion of patients who had a GP (red line) or HES (blue line) diagnosis shows a similar pattern of increase over this period. Together, this represents an increase from 76.3 to $95.7 \%$ in the percentage who had a prior diagnosis in GP and/or HES records. In addition, trends in codes indicating GP dementia awareness showed a steady increase over this period, while the use of GP administrative codes quickly increased once they were introduced with QOF circa 2006. Putting all these codes together, the percentage of deaths with dementia mentioned on the death certificate that also had supporting evidence in either GP and/or HES records rose from $77.2 \%$ to 2001 to $97.7 \%$ in 2015 .

\section{Discussion}

\section{Summary of main findings}

There is increased recording of dementia diagnoses across both primary and secondary care between 2001 
Table 1 Summary of dementia recording among all deaths from 2001-2015 ( $n=207,068)$

\begin{tabular}{|c|c|c|c|c|c|c|c|c|c|c|c|c|c|c|}
\hline \multirow{3}{*}{$\begin{array}{l}\text { Year of } \\
\text { Death }\end{array}$} & \multirow{3}{*}{$\begin{array}{l}\text { Total } \\
\text { Deaths }\end{array}$} & \multicolumn{5}{|c|}{ Dementia recording on Death Certificate } & \multicolumn{8}{|c|}{ Prior Dementia diagnosis in GP or HES records } \\
\hline & & \multicolumn{2}{|c|}{ Any mention } & \multicolumn{3}{|c|}{ Listed as underlying cause only } & \multicolumn{2}{|c|}{ GP diagnosis } & \multicolumn{2}{|c|}{ HES diagnosis } & \multicolumn{2}{|c|}{$\begin{array}{l}\text { GP or HES } \\
\text { diagnosis plus } \\
\text { death } \\
\text { certificate }\end{array}$} & \multicolumn{2}{|c|}{$\begin{array}{l}\text { GP or HES } \\
\text { diagnosis but } \\
\text { not on death } \\
\text { certificate }\end{array}$} \\
\hline & & $\mathrm{n}$ & $\begin{array}{l}\% \text { of } \\
\text { total }\end{array}$ & $\mathrm{n}$ & $\begin{array}{l}\% \text { of } \\
\text { total }\end{array}$ & $\begin{array}{l}\% \text { of dementia } \\
\text { deaths only }^{\mathrm{a}}\end{array}$ & $\mathrm{n}$ & $\begin{array}{l}\% \text { of } \\
\text { total }\end{array}$ & $\mathrm{n}$ & $\begin{array}{l}\% \text { of } \\
\text { total }\end{array}$ & $\mathrm{n}$ & $\begin{array}{l}\% \text { of } \\
\text { total }\end{array}$ & $\mathrm{n}$ & $\begin{array}{l}\% \text { of } \\
\text { total }\end{array}$ \\
\hline 2001 & 13,796 & 733 & $5.3 \%$ & 376 & $2.7 \%$ & $51.3 \%$ & 1,077 & $7.8 \%$ & 1,079 & $7.8 \%$ & 1,651 & $12.0 \%$ & 1,092 & $7.9 \%$ \\
\hline 2002 & 14,099 & 820 & $5.8 \%$ & 387 & $2.7 \%$ & $47.2 \%$ & 1,242 & $8.8 \%$ & 1,322 & $9.4 \%$ & 1,898 & $13.5 \%$ & 1,280 & $9.1 \%$ \\
\hline 2003 & 14,386 & 919 & $6.4 \%$ & 403 & $2.8 \%$ & $43.9 \%$ & 1,375 & $9.6 \%$ & 1,470 & $10.2 \%$ & 2,105 & $14.6 \%$ & 1,358 & $9.4 \%$ \\
\hline 2004 & 13,997 & 927 & $6.6 \%$ & 398 & $2.8 \%$ & $42.9 \%$ & 1,367 & $9.8 \%$ & 1,515 & $10.8 \%$ & 2,090 & $14.9 \%$ & 1,316 & $9.4 \%$ \\
\hline 2005 & 13,863 & 968 & $7.0 \%$ & 419 & $3.0 \%$ & $43.3 \%$ & 1,399 & $10.1 \%$ & 1,635 & $11.8 \%$ & 2,130 & $15.4 \%$ & 1,299 & $9.4 \%$ \\
\hline 2006 & 13,790 & 1,014 & $7.4 \%$ & 414 & $3.0 \%$ & $40.8 \%$ & 1,420 & $10.3 \%$ & 1,705 & $12.4 \%$ & 2,196 & $15.9 \%$ & 1,309 & $9.5 \%$ \\
\hline 2007 & 13,753 & 1,087 & $7.9 \%$ & 451 & $3.3 \%$ & $41.5 \%$ & 1,602 & $11.6 \%$ & 1,886 & $13.7 \%$ & 2,361 & $17.2 \%$ & 1,386 & $10.1 \%$ \\
\hline 2008 & 14,163 & 1,287 & $9.1 \%$ & 525 & $3.7 \%$ & $40.8 \%$ & 1,802 & $12.7 \%$ & 2,169 & $15.3 \%$ & 2,653 & $18.7 \%$ & 1,507 & $10.6 \%$ \\
\hline 2009 & 13,562 & 1,374 & $10.1 \%$ & 547 & $4.0 \%$ & $39.8 \%$ & 1,768 & $13.0 \%$ & 2,276 & $16.8 \%$ & 2,710 & $20.0 \%$ & 1,472 & $10.9 \%$ \\
\hline 2010 & 13,921 & 1,478 & $10.6 \%$ & 580 & $4.2 \%$ & $39.2 \%$ & 1,859 & $13.4 \%$ & 2,486 & $17.9 \%$ & 2,899 & $20.8 \%$ & 1,562 & $11.2 \%$ \\
\hline 2011 & 13,607 & 1,565 & $11.5 \%$ & 988 & $7.3 \%$ & $63.1 \%$ & 1,931 & $14.2 \%$ & 2,643 & $19.4 \%$ & 3,035 & $22.3 \%$ & 1,588 & $11.7 \%$ \\
\hline 2012 & 14,058 & 1,823 & $13.0 \%$ & 1,149 & $8.2 \%$ & $63.0 \%$ & 2,150 & $15.3 \%$ & 2,954 & $21.0 \%$ & 3,369 & $24.0 \%$ & 1,675 & $11.9 \%$ \\
\hline 2013 & 14,274 & 1,868 & $13.1 \%$ & 1,160 & $8.1 \%$ & $62.1 \%$ & 2,307 & $16.2 \%$ & 3,026 & $21.2 \%$ & 3,469 & $24.3 \%$ & 1,716 & $12.0 \%$ \\
\hline 2014 & 13,718 & 1,909 & $13.9 \%$ & 1,250 & $9.1 \%$ & $65.5 \%$ & 2,394 & $17.5 \%$ & 3,075 & $22.4 \%$ & 3,665 & $26.7 \%$ & 1,756 & $12.8 \%$ \\
\hline 2015 & 12,081 & 1,855 & $15.4 \%$ & 1,206 & $10.0 \%$ & $65.0 \%$ & 2,562 & $21.2 \%$ & 2,870 & $23.8 \%$ & 3,381 & $28.0 \%$ & 1,605 & $13.3 \%$ \\
\hline All & 207,068 & 19,627 & $9.5 \%$ & 10,253 & $5.0 \%$ & $52.2 \%$ & 26,255 & $12.7 \%$ & 32,111 & $15.5 \%$ & 39,612 & $19.1 \%$ & 21,921 & $10.6 \%$ \\
\hline
\end{tabular}

a Denominator here is all deaths with any mention of dementia on death certificate

and 2015, and this is reflected in an increased number of deaths recording dementia, both as a contributory or underlying cause, a trend also seen in national data [3]. By 2015 , the vast majority (97.7\%) of deaths with dementia mentioned on the death certificate had existing evidence of dementia recorded in primary and/or secondary care records. However, over the same period, the percentage of people dying with dementia, but not of dementia has substantially increased. In particular, while the percentage of deaths with dementia mentioned on the death certificate, but not as underlying cause, has increased, this has not kept pace with the rise in dementia diagnoses in primary and secondary care records. Thus by 2015 only half of those dying with dementia have it mentioned on the death certificate as a contributory cause. While not surprising, it does mean that death certification provides an inadequate picture of the prevalence of dementia at the time of death.

\section{Strengths and limitations}

One of the major strengths of this study is the breadth of geographical coverage and basis in an unselected population from a large, validated longitudinal primary care database that is broadly representative of the population [13]. The time period assessed includes key dementia related policy changes to QOF [8] and in contrast to some other studies, we have restricted to practices that contributed data over the entire study period for consistency.

In addition to the comprehensive data linkage between the databases [13], HES has universal coverage in England, which is a key strength [15], although due to variation in quality of coding, data about co-morbidities such as dementia may be entered inconsistently across sites. As well as issues with missing data HES does not include outpatient data so any patients with dementia who attended a dementia/memory assessment clinic will not have been coded in HES, though diagnoses from such letters should have been coded in primary care records and therefore included in CPRD. HES-CPRD data first became available from April 1997 [15], which may impact on the results as deaths from earlier in the study period would have a maximum of three years of prior hospital data. The time period assessed includes policy change related to hospital recording of dementia introduced in 2012 [11].

We were constrained to using data for England only, as CPRD linkage to HES and ONS is limited to this area [14]. Data quality in CPRD is reliant on accurate coding by primary care staff and there may be variability in 


\section{1}

$\mathrm{N}=13,796$ total deaths $(100 \%)$

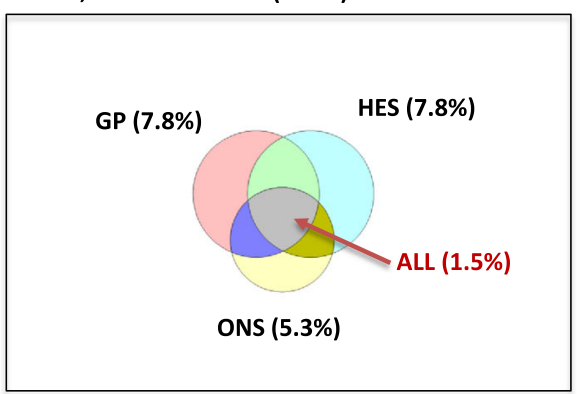

$13.2 \%$ of all deaths have dementia recorded in GP, HES or ONS

\section{5}

$\mathrm{N}=12,081$ total deaths $(100 \%)$

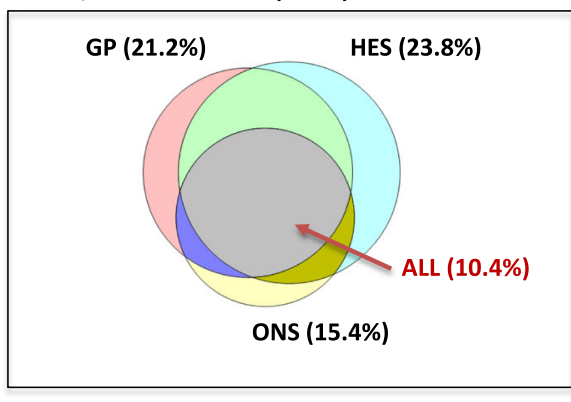

$\mathbf{2 8 . 6 \%}$ of all deaths have dementia recorded in GP, HES or ONS

Fig. 1 Triangulation of GP, HES and ONS recording of dementia in 2015 vs. 2001 for all deaths. Footnote: All percentages are for deaths from any cause indicated by; (i) for GP (diagnostic codes), (ii) for HES (diagnostic codes) and (iii) for ONS (any mention of dementia on death certificate). Approximate scaling for each circle has been used to represent the relative contribution of each of the data sources.

coding across sites, as well as issues with the Read codes associated with dementia as coding changes were introduced during the study period. This is illustrated by the sharp increase in recorded GP dementia awareness after 2006 which corresponded with the introduction of new dementia related codes incentivising QOF after 2006 $[7,8]$. There was also a coding change affecting ONS records in 2010, with a modification in the rules on death certification, aimed at improving the accuracy of recording of the underlying cause of death [21]. Whilst this did not impact greatly on the all-cause dementia rates (Supplementary Fig. 2), it has affected the subtypes of dementia recorded, as a correction was made to the coding of vascular dementia and previously coded cerebrovascular disease was corrected to vascular dementia [22]. As a result of these coding changes there may have been some changes in the proportions of underlying cause within the anymention of dementia group at the 2010 to 2011 transition. After this coding change the number of deaths with any mention of dementia on the death certificate continued to rise.

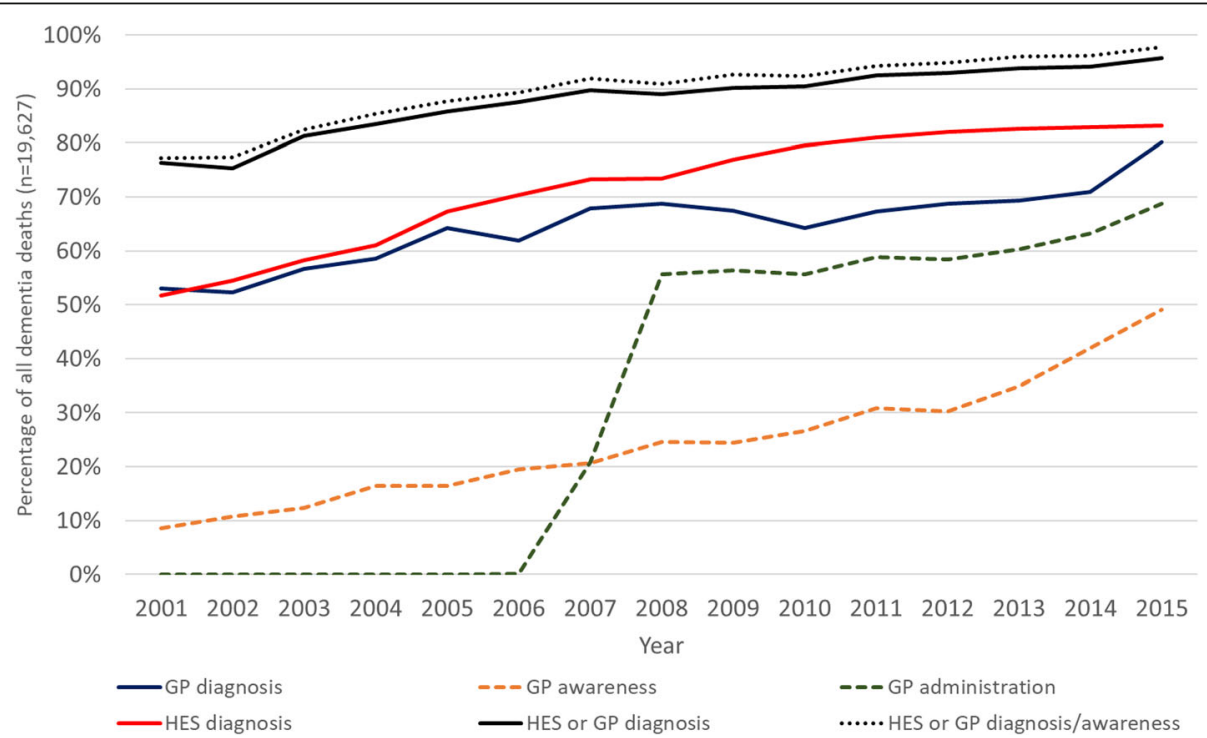

Fig. 2 Trends in the recording of dementia diagnoses and other information in GP and HES among all death certifications with mention of dementia 2001-2015 ( $n=19,627)$. Footnote: Definition of categories was as follows: GP diagnosis = includes specific Read codes indicating a diagnosis for dementia, GP awareness = includes Read codes related to suspected memory impairment or other codes indicative of Dementia, GP administration = Other administrative codes on GP system relating to dementia, Any GP recording = Any of GP diagnosis, awareness or administration, HES diagnosis = refers to admission records which mention dementia either as primary cause of admission or other 


\section{Comparison with other studies}

A recent systematic review [23] of the validity of dementia diagnoses in routinely collected UK electronic health records reported generally high validity, although all studies included were at significant risk of bias. Individual studies have also previously addressed recording of dementia across different data sources. Brown et al. found higher levels of agreement between GP and HES data $(95 \%)$ than we reported, but in a small sample of women only $(n=340)$ [24]. Perera et al. linked dementia diagnoses from a London mental health database to ONS mortality data from 2006 to 2013 and reported an increase in dementia recording over this period, consistent with our findings [25]. A much larger study (47,386 people with dementia) examined the diagnostic validity of dementia in CPRD records from 1998 to 2010, also using HES and ONS records, as we did [26]. Whilst not directly comparable to our study, as they did not examine trends over time and we provide more recent data; they found that $8 \%$ had evidence of a dementia diagnosis across all three sources during this period, compared to our figures of $1.5 \%$ in 2001 and $10.4 \%$ in 2015 [26].

In UK, the Cognitive Functioning in Ageing Study (CFAS) provided important data on trends over time (1989-2016), in accuracy of death certification of dementia, from their large cohort study of patients aged $>$ 65 years $(n=26,699)$ [4,27]. They demonstrated an increase in overall unadjusted prevalence of dementia on death certificates (5.3 to $25.9 \%$ ) and an increase in sensitivity of dementia reporting on death certificates compared to a gold-standard of study clinical diagnosis of dementia (from $21 \%$ in CFAS I to $45.2 \%$ in CFAS II) [ 4 , 27]. These are consistent with our findings, indicating a similar trend of increased recording of dementia on death certificates, but with a recognition that death certificates still give an inadequate picture of the number of people dying with dementia.

It is not generally well understood what influences decisions regarding diagnoses recorded in the death certificate [28]. During our study period we observed a steady increase in dementia appearing on death certificates between 2001 and 2015, while at the same time agespecific incidence rates of dementia were falling in the UK [27]. This trend has been replicated in other cohort studies in Europe and North America, suggesting that over the last 25 years the incidence rate may have declined by $13 \%$ per decade [29]. It seems plausible that the improvements in the management of cardiovascular disease over time has contributed to this reduction, particularly for vascular dementia [30]. This might also result in a deferral of dementia to older age, however with people living longer, age at death will have increased over this time too, so the likelihood of having dementia by the time of death would almost certainly have risen as well. This could explain the increasing numbers of deaths from dementia observed in this study. Other potential contributing factors over the study period could include the increased public and medical awareness due to activity by campaigning groups and government, as well as increased referral access to memory clinics. The National Dementia Strategy, launched in 2009, has previously been shown to be associated with a significant increase in dementia diagnosis rates and prescriptions of antidementia drugs [31]. Dementia deaths in this study with a prior diagnosis of dementia in both electronic GP and hospital records has increased from $76.3 \%$ to 2001 to $95.7 \%$ in 2015 which may reflect a change in clinicians' attitudes and less reluctance in entering a diagnosis of dementia due to concerns about stigma and increased case finding and confidence in management [32].

\section{Implications for practice and public health policy}

Changes in QOF in primary care and in policy relating to hospital inpatients, both designed to increase the diagnosis rate of dementia, have led to a greater awareness of dementia in clinical practice and increased recording of dementia on death certificates as a primary or contributory cause. Nevertheless, only half of those dying with a prior diagnosis of dementia had dementia recorded on their death certificate in 2015. The high and increasing proportion of people recognized to be dying "with" dementia (in addition to those dying "of" dementia) has important cost and workforce implications for both health and social care service planning for care of older people.

\section{Further work}

The introduction of Independent Medical Examiners (IME) from April 2019 [33] could impact on dementia recording rates, as the role of the IME extends to discussions with relatives before deciding on cause of death. Repeating the study in the future and comparing it to current findings may give further insights into dementia detection and recording in primary care. Previous work has demonstrated significant regional variations in dementia recording [34] this could also be investigated as a potential explanatory factor.

\section{Conclusions}

Our study demonstrates that between 2001 and 2015 in England, dementia recording in GP electronic records, hospital records and death certification increased. By 2015 the vast majority of deaths mentioning dementia on the death certificate had prior evidence of diagnosis in primary and/or secondary care (97.7\%); a marked improvement from 2001. It emphasizes that when 
dementia is mentioned on death certificates there is good evidence backing this up. However, death certificates still give an inadequate picture of the total number of people dying with dementia; in 2015 only half of those people dying with dementia had dementia recorded on their death certificates.

\section{Abbreviations}

CFAS: Cognitive Functioning in Ageing Study; CPRD: Clinical Practice Research Datalink; DIS: Dementia Identification Scheme; DES: Directed Enhances Services; GP: General Practice; HES: Hospital Episode Statistics; ICD: International Classification of Diseases; IME: Independent Medical Examiners; MCCD: Medical Certificate of the Cause of Death; NHS: National Health Service; ONS: Office for National Statistics; QOF: Quality and Outcomes Framework

\section{Supplementary Information}

The online version contains supplementary material available at https://doi. org/10.1186/s12877-021-02306-7.

\section{Additional file 1.}

\section{Acknowledgements}

Not applicable.

\section{Authors' contributions}

SA, IC, TH, SD, DG and DS all contributed to the design and concept of the study, interpretation of the data, and writing the manuscript. IC carried out the data extractions and analysis. All authors have read and approved the final version of the manuscript.

\section{Funding}

None.

\section{Availability of data and materials}

The data that support the findings of this study are available from CPRD but restrictions apply to the availability of these data, which were used under license for the current study, and so are not publicly available.

\section{Declarations}

\section{Ethics approval and consent to participate}

Access to CPRD data is subject to protocol approval by an Independent Scientific Advisory Committee (ISAC), Medicines and Healthcare Products Regulatory Agency, London, UK. The main study protocol was approved in May 2017 (ISAC Protocol17_031R).

\section{Consent for publication}

Not applicable.

\section{Competing interests}

The authors declare that they have no competing interests.

Received: 30 June 2020 Accepted: 27 May 2021

Published online: 21 June 2021

References

1. Prince $M$, Knapp $M$, Guerchet $M$, et al. Dementia UK: Second edition Overview. 2014: https://www.alzheimers.org.uk/sites/default/files/migrate/ downloads/dementia_uk_update.pdf. Accessed 25-03-2021.

2. Sibbett RA, Russ TC, Deary IJ, Starr JM. Dementia ascertainment using existing data in UK longitudinal and cohort studies: a systematic review of methodology. BMC Psychiatry 2017;17

3. Office for National Statistics. Deaths registered in England and Wales (series DR). 2018. 2018: https://www.ons.gov.uk/peoplepopulationandcommunity/ birthsdeathsandmarriages/deaths/bulletins/deathsregistrationsummaryta bles/2018. Accessed 25-03-2021.
4. Gao L, Calloway R, Zhao E, et al. Accuracy of death certification of dementia in population-based samples of older people: analysis over time. Age Ageing. 2018;47(4):589-94.

5. Department of Health. Living well with dementia: A National Dementia Strategy. Department of Health; 2009: https://assets.publishing.service.gov. uk/government/uploads/system/uploads/attachment_data/file/168220/dh 094051.pdf. Accessed 06-04-2020.

6. GOV.UK. Prime Minister's challenge on dementia 2020. Department of Health \& Social Care; 2015: https://www.gov.uk/government/publications/ prime-ministers-challenge-on-dementia-2020/prime-ministers-challenge-ondementia-2020. Accessed 25-03-2021.

7. NHS Digital. Quality and Outcomes Framework. NHS Digital; 2021: https:// digital.nhs.uk/data-and-information/data-collections-and-data-sets/datacollections/quality-and-outcomes-framework-qof. Accessed 17-03-2021.

8. NHS England. 2014/15 General Medical Services (GMS) Contract Quality and Outcomes Framework (QOF). Guidance for GMS Contracts 2014/15. 2014: http://www.nhsemployers.org/ /media/Employers/Publications/2014 \%201 $5 \% 20$ QOF\%20guidance\%20stakeholders.pdf. Accessed 25-03-2021.

9. Liu D, Green E, Kasteridis P, et al. Incentive schemes to increase dementia diagnoses in primary care in England: a retrospective conort study of unintended consecuences. Br J Gen Pract. 2019;69(680):E154-E63.

10. World Health Organisation. International Classification of Diseases 10th Revision (ICD-10). Geneva2004: https://www.who.int/classifications/icd/ICD-1 0_2nd_ed_volume2.pdf. Accessed 25-03-2021.

11. Department of Health. Using the Commissioning for Quality and Innovation (CQUIN) payment framework Guidance on new national goals for 2012 2013 London: Department of Health and Social Care; 2012: https://www. gov.uk/government/publications/using-the-commissioning-for-quality-andinnovation-cquin-payment-framework-guidance-on-new-national-goals-for-2 012-13. Accessed 25-03-2021.

12. Chisholm J. The Read clinical classification. BMJ. 1990;300(6732):1092.

13. Herrett E, Gallagher AM, Bhaskaran K, et al. Data resource profile: Clinical Practice Research Datalink (CPRD). Int J Epidemiol. 2015;44(3):827-36.

14. Padmanabhan $\mathrm{S}$, Carty $\mathrm{L}$, Cameron $\mathrm{E}$, et al. Approach to record linkage of primary care data from Clinical Practice Research Datalink to other healthrelated patient data: overview and implications. Eur J Epidemiol. 2019:34(1):91-9.

15. Herbert A, Wijlaars L, Zylbersztejn A, Cromwell D, Hardelid P. Data resource profile: hospital episode statistics admitted patient care (HES APC). Int J Epidemiol. 2017;46(4):1093-+

16. Herrett E, Gallagher A, Bhaskaran K, et al. Completeness of key variables in the Clinical Practice Research Datalink (CPRD). Pharmacoepidemiol Drug Saf. 2015;24:586-7.

17. Gallagher AM, Dedman D, Padmanabhan S, Leufkens HGM, de Vries F. The accuracy of date of death recording in the Clinical Practice Research Datalink GOLD database in England compared with the Office for National Statistics death registrations. Pharmacoepidemiol Drug Saf. 2019;28(5):563-9.

18. Harshfield A, Abel GA, Barclay S, Payne RA. Do GPs accurately record date of death? A UK observational analysis. BMJ Support Palliat Care 2018: bmjspcare-2018-001514.

19. GOV.UK. Completing a medical certificate of cause of death (MCCD) 2020: https://www.gov.uk/government/publications/quidance-notes-forcompleting-a-medical-certificate-of-cause-of-death. Accessed 25-03-2021.

20. Venn Diagram Plotter. Pacific Northwest National Library: https://omics.pnl. gov/software/venn-diagram-plotter. Accessed 25-03-2021.

21. The General Register Office for England and Wales. Guidance for doctors completing Medical Certificates of Cause of Death in England and Wales. 2010: https://www.gro.gov.uk/Images/medcert_July_2010.pdf. Accessed 18-03-2021.

22. Office for National Statistics. Changing trends in mortality: a cross-UK comparison, 1981 to 2016. 2018: https://www.ons.gov.uk/peoplepopulationa ndcommunity/birthsdeathsandmarriages/lifeexpectancies/articles/cha ngingtrendsinmortality/acrossukcomparison1981 to2016\#quality-andmethodology. Accessed 25-03-2021.

23. McGuinness LA, Warren-Gash C, Moorhouse LR, Thomas SL. The validity of dementia diagnoses in routinely collected electronic health records in the United Kingdom: A systematic review. Pharmacoepidemiol Drug Saf. 2019; 28(2):244-55.

24. Brown A, Kirichek O, Balkwill A, et al. Comparison of dementia recorded in routinely collected hospital admission data in England with dementia recorded in primary care. Emerging themes in epidemiology. 2016;13:11-1. 
25. Perera G, Stewart R, Higginson IJ, Sleeman KE. Reporting of clinically diagnosed dementia on death certificates: retrospective cohort study. Age Ageing. 2016;45(5):667-72.

26. Pujades-Rodriguez M, Assi V, Gonzalez-lzquierdo A, et al. The diagnosis, burden and prognosis of dementia: A record-linkage cohort study in England. PLoS One. 2018;13(6):e0199026.

27. Matthews FE, Stephan BCM, Robinson L, et al. A two decade dementia incidence comparison from the Cognitive Function and Ageing Studies I and II. Nature Communications 2016;7.

28. McAllum C, St George I, White G. Death certification and doctors' dilemmas: a qualitative study of GPs' perspectives. Br J Gen Pract. 2005;55(518):677-83.

29. Wolters FJ, Chibnik LB, Waziry R, et al. Twenty-seven-year time trends in dementia incidence in Europe and the United States The Alzheimer Cohorts Consortium. Neurology. 2020;95(5):E519-E31.

30. Roehr S, Pabst A, Luck T, Riedel-Heller SG. Is dementia incidence declining in high-income countries? A systematic review and meta-analysis. Clin Epidemiol. 2018:10:1233-47.

31. Mukadam N, Livingston G, Rantell K, Rickman S. Diagnostic rates and treatment of dementia before and after launch of a national dementia policy: an observational study using English national databases. BMJ Open. 2014;4(1):e004119.

32. Russell $\mathrm{P}$, Banerjee $\mathrm{S}$, Watt J, et al. Improving the identification of people with dementia in primary care: evaluation of the impact of primary care dementia coding guidance on identified prevalence. Bmj Open. 2013;3(12):4.

33. Fletcher A, Coster J, Goodacre S. Impact of the new medical examiner role on patient safety. BMJ-British Medical Journal 2018;363.

34. Walker IF, Lord PA, Farragher TM. Variations in dementia diagnosis in England and association with general practice characteristics. Primary Health Care Research Development. 2017;18(3):235-41.

\section{Publisher's Note}

Springer Nature remains neutral with regard to jurisdictional claims in published maps and institutional affiliations.

Ready to submit your research? Choose BMC and benefit from:

- fast, convenient online submission

- thorough peer review by experienced researchers in your field

- rapid publication on acceptance

- support for research data, including large and complex data types

- gold Open Access which fosters wider collaboration and increased citations

- maximum visibility for your research: over $100 \mathrm{M}$ website views per year

At $\mathrm{BMC}$, research is always in progress.

Learn more biomedcentral.com/submissions 